\title{
Climate change and the distribution of climatic resources for tourism in North America
}

\author{
Daniel Scott*, Geoff McBoyle, Michael Schwartzentruber
}

Department of Geography, University of Waterloo, 200 University Avenue West, Waterloo, Ontario N2L 3G1, Canada

\begin{abstract}
Tourism is a major sector of the global economy, and it is strongly influenced by climate. At some travel destinations, climate represents the natural resource on which the tourism industry is predicated. Global climate change has the potential to alter the distribution of climate assets among tourism destinations, with implications for tourism seasonality, demand and travel patterns. Changes in the length and quality of the tourism season have considerable implications for the long-term profitability of tourism enterprises and competitive relationships between destinations. This analysis utilizes a 'tourism climate index' (TCI) that incorporates 7 climate variables relevant to general tourism activities (i.e. sightseeing) to assess the spatial and temporal distribution of climate resources for tourism in North America under baseline conditions (1961-1990) and 2 climate change scenarios (CGCM2-B2 and HadCM3-A1F1) for the 2050s and 2080s. The analysis found that a substantive redistribution of climate resources for tourism will be possible in the later decades of the 21st century, particularly in the warmer and wetter HadCM3-A1F1 scenario. The number of cities in the USA with 'excellent' or 'ideal' TCI ratings (TCI > 80) in the winter months is likely to increase, so that southern Florida and Arizona could face increasing competition for winter sun holiday travelers and the seasonal 'snowbird' market (retirees from Canada and the northern states of the USA, who spend 2 to 6 mo in winter peak and optimal climate destinations). In contrast, lower winter TCI ratings in Mexico suggest it could become less competitive as a winter sun holiday destination. In Canada, a longer and improved warm-weather tourism season may enhance its competitiveness in the international tourism marketplace, with potentially positive implications for its current international tourism account deficit.
\end{abstract}

KEY WORDS: Tourism $\cdot$ Tourism climate index $\cdot$ Climate change $\cdot$ North America

\section{INTRODUCTION}

Tourism is a major sector of the global economy. International tourism grew by $7.1 \% \mathrm{yr}^{-1}$ from 1950 to 1995, and the 693 million international tourist arrivals worldwide in 2001 generated receipts of US\$718 billion (WTO 1998, 2002). It is projected that by 2020, there will be 1.6 billion international tourist arrivals, spending over US\$2 trillion worldwide (WTO 1998). North America is a major tourist destination, with the USA, Canada and Mexico among the top 10 for international tourist arrivals, ranking 3rd (46 million), 8th (20 million) and 9th (20 million), respectively (WTO 2002). The USA ranked number one in international tourism receipts, generating US\$112 billion, while Canada ranked 8th (US\$16.2 billion) and Mexico 12th (US\$13 billion) (WTO 2002). Domestic tourism within the USA and Canada is estimated to be several times greater than international tourism, with domestic travelers spending an estimated US\$490 billion in the USA in 2003 (Travel Industry Association of America 2004) and US\$26 billion in Canada in 2000 (CBC 2004).

Weather and climate are key influences on the tourism sector worldwide (Smith 1993, Boniface \& Cooper 1994, Perry 1997), affecting the length and quality of tourism seasons and the environmental resources that draw tourists to destinations (e.g. health of coral reefs for diving, water levels for boating, and 
snow cover for skiing). A $1^{\circ} \mathrm{C}$ warmer than average summer season was found to increase domestic tourism expenditures in Canada by $4 \%$ (Wilton \& Wirjanto 1998). Similar patterns were observed in the UK during unusually warm summers (Giles \& Perry 1998). Agnew (1995) also found that in the UK, tourism spending abroad increased following a cold winter. Giles \& Perry (1998) found that the exceptional summer of 1995 in the UK had the opposite effect, resulting in a drop in outbound tourism.

Climate is both a 'push' and a 'pull' factor in tourism and for some destinations, represents the primary resource on which tourism is predicated. 'Escaping winter weather' was a prime travel motivation for $23 \%$ of Canadian respondents (OMTR 2002). Jorgensen \& Solvoll (1996) estimated that $84 \%$ of tour charters from Norway were to 'sun destinations.' An annual survey of German traveller behaviour and tourism-related attitudes revealed that $43 \%$ of Germans indicated weather was a major importance in choice of holiday destination (third in importance behind landscape at $51 \%$ and price at $50 \%$ ) (Lohmann \& Kaim 1999).

Despite the importance of climatic resources, comparatively few investigations have examined the relationships between climate and tourism (de Freitas 1990, Wall 1992, Smith 1993, Perry 1997). Wall (1998), Viner \& Amelung (2003), and Scott (2004) have expressed concern that research to assess the potentially profound impacts of global climate change on tourism remains similarly limited. As Viner \& Amelung (2003) and Scott (2004) have indicated, relative to other economic sectors (e.g. agriculture and forestry), tourism has received far less attention by the climate change impacts research community, irrespective of its current and growing significance to the global economy. More recently, the salience of climate change has been recognized by tourism stakeholders (governments, industry, and scientists), as delegates from over 45 nations endorsed the Djerba Declaration on Climate Change and Tourism (WTO 2003).

One of the most direct impacts of projected climate change on tourism will be the redistribution of climatic assets among tourism regions, with subsequent implications for tourism seasonality, tourism demand, and travel patterns. Changes in the length and quality of the warm-weather tourism season could have considerable implications for competitive relationships between destinations and therefore the profitability of tourism enterprises. This is particularly the case where climate is the principal tourism resource (e.g. the Caribbean, Polynesia, the Mediterranean).

An important methodological challenge to a macroscale analysis of the impact of global climate change on the distribution of climate resources for tourism is a standardized metric to assess climate conditions for tourism, and to measure their change. As de Freitas (2003) indicated, tourists respond to the integrated effects of climate (e.g. temperature, humidity, wind, rain, sunshine). A climate index approach is one way researchers have attempted to represent the multifaceted nature of the climate resource for tourism. Several indices have been developed over the last $30 \mathrm{yr}$ to assess the suitability of climate for tourism activities (Pegay 1961, Heurtier 1968, Besancenot et al. 1978, Mieczkowski 1985, Becker 2000, Morgan et al. 2000). These indices were developed with the intent of providing an assessment of the suitability of climate for tourism that could be used in decision making both by tourists and the tourism industry. Tourists and tour operators could use an index to select the best time and place for vacation travel or to plan activities appropriate to the expected climate. Tourism planners could use an index to assess a destination for possible tourism development and to plan resort development programs. Tourism marketers could use an index to promote visitation outside the peak period (and reduce tourism seasonality), to objectively compare their tourism product to other more well known destinations, and to provide potential visitors with information to reduce the gap between expected (or promoted) and real weather conditions, so as to reduce the potential for dissatisfaction (and increase return visits). These indices were not developed as predictors of tourism demand, but to assess the supply and quality of climate resources for tourism. A similar index approach to resource supply assessment for tourism was used by Boyd et al. (1994) to assess multiple characteristics of a landscape for potential eco-tourism development.

Mieczkowski's (1985) 'tourism climate index' (TCI) was selected for use in this analysis based on 3 main characteristics of the index. The TCI is the most comprehensive climate index developed specifically for tourism (1). The TCI was originally conceptualized as a composite measure to systematically assess the climatic elements most relevant to the quality of the tourism experience for general tourism activities (i.e. the most common tourism activities of sight-seeing and shopping; Jansen-Verbeke 2001) that occur everywhere from urban centers to national parks (2). An index represents something for which there is no easy measurement. Therefore any climate index for tourism which represents the integrative effects of climate variables will not represent an aggregate measure for every tourist's climate preferences, as these vary (Limb \& Spellman 2001), nor can it rate the climate resource for specific tourism activities like skiing or beach use, where different climate preferences are likely. Mieczkowski's (1985) TCI was also designed to use climate data which is widely available for tourist destinations worldwide (3). The comprehensive nature of 
Table 1. Components of Mieczkowski's (1985) tourism climate index (TCI)

\begin{tabular}{|c|c|c|c|c|}
\hline Abbrev. & Sub-index & Monthly climate variables & Influence on TCI & Weight $(\%)$ \\
\hline CID & Daytime comfort & $\begin{array}{l}\text { Max. daily temperature and } \\
\text { min. daily relative humidity }\end{array}$ & $\begin{array}{l}\text { Thermal comfort during max. } \\
\text { tourist activity }\end{array}$ & 40 \\
\hline CIA & Daily comfort & $\begin{array}{l}\text { Mean daily temperature and } \\
\text { mean daily relative humidity }\end{array}$ & Thermal comfort over $24 \mathrm{~h}$ & 10 \\
\hline $\mathrm{P}$ & Precipitation & Total precipitation & Negative impact of precipitation & 20 \\
\hline $\mathrm{S}$ & Sunshine & Total hours of sunshine & Influence of the amount of sunshine & 20 \\
\hline $\mathrm{W}$ & Wind & Average wind speed & Influence of average wind speed & 10 \\
\hline
\end{tabular}

the TCI, its applicability to general tourism activities, and data availability (for both current climate and from climate change scenarios) made the TCI well suited to a macro-scale analysis of potential future changes in climate resources for tourism.

The purpose of this study was to investigate current patterns and potential changes in the spatial and temporal distribution of the climate resource for tourism in North America using the TCI and 2 climate change scenarios. Section 2 describes the characteristics of the TCI and methodological procedures; Section 3 assesses the current (1961-1990) distribution of climate resources for general tourism activities in North America and projections for the 2050s and 2080s under 2 climate change scenarios. A discussion of the potential implications of the projected changes for the tourism industry concludes the paper.

\section{METHODS}

\subsection{Tourism climate index of Mieczkowski (1985)}

The TCI developed by Mieczkowski (1985) was based on previous research related to climate classifications for tourism and recreation (Heurtier 1968, Crowe 1976) and theoretical considerations from the biometeorological literature related to human comfort, particularly with reference to tourism activities (Burnet 1963, Dammann 1964, Hofer 1967, Heurtier 1968, Danilova 1973, Kandror et al. 1974). The reader is referred to the original paper for additional details of this large body of literature used by Mieczkowski (1985) in the conceptual and methodological development of the TCI.

Initially, Mieczkowski (1985) identified 12 monthly climate variables from the literature as pertinent to an index for tourism. Meteorological data limitations reduced the number of climate variables that were integrated into the TCI to 7 : monthly means for maximum daily temperature, mean daily temperature, minimum daily relative humidity, mean daily relative humidity, total precipitation, total hours of sunshine, average wind speed (Table 1). With the relative weightings of the index components incorporated, the TCI takes on the following expression:

$$
\mathrm{TCI}=2[(4 \times \mathrm{CID})+\mathrm{CIA}+(2 \times \mathrm{P})+(2 \times \mathrm{S})+\mathrm{W}]
$$

The main modification to the original TCI in this analysis was the replacement of 'effective temperature' (ET) with 'apparent temperature' (AT) (Steadman 1984) or 'heat index' as it is referred to in applications in the USA, as the measure of thermal comfort in the TCI. This change was made because the older ET approach has been found to overestimate the effects of humidity. The other difference relative to the original TCI analysis is related to the period of record for climate data. Though not specified, it is presumed that Mieczkowski (1985) used climate data or climate normals for 1951-1980. The climate data used in this study are from the 1961-1990 period.

The TCI used a standardized rating system, ranging from 5 (optimal) to -3 (extremely unfavorable) to provide a common basis of measurement for the climate variables that made up the index. The total range of TCI values is -30 to 100 . Similar to a number of other climate-based indices (e.g. UV index), the TCI rating scale was divided into 10 qualitative, descriptive categories (Table 2) to facilitate interpretation.

Table 2. Rating categories in the Mieczkowski (1985) tourism climate index

\begin{tabular}{|ll|}
\hline TCI score & \multicolumn{1}{c|}{ Category } \\
\hline 90 to 100 & Ideal \\
80 to 89 & Excellent \\
70 to 79 & Very good \\
60 to 69 & Good \\
50 to 59 & Acceptable \\
40 to 49 & Marginal \\
30 to 39 & Unfavourable \\
20 to 29 & Very unfavourable \\
10 to 19 & Extremely unfavourable \\
-30 to 9 & Impossible \\
\hline
\end{tabular}


The rating system of the climate variables in the TCI and the relative weightings of the components of the index were based on available biometeorological literature and expert opinion, but are ultimately subjective. The subjectivity of Mieczkowski's (1985) TCI has been the central critique of this index (de Freitas 2001, 2003), but one that applies to all other climate indices for tourism, with the exception of Morgan et al.'s (2000) beach climate index, which was based on a survey of beach users in the UK. While conceptually superior to other indices because of its validation with recreational users, even Morgan et al.'s (2000) index has a shortcoming in that it is mainly based only on beach users in the UK, whose activities, dress and climate preferences are likely to be very different from those of beach goers in the Mediterranean, Caribbean, or Australia. That the TCI was not validated against stated tourist climate preferences is the central weakness of the Mieczkowski (1985) index and a central improvement required in future work. The results of the TCI and this analysis therefore represent one expert opinion-based assessment of the climate resource for tourism. Other interpretations and findings are possible using indices that are constructed differently.

Despite its limitations, the utility of the TCI for this scoping analysis of possible changes in the climate resource for tourism under climate change remains its systematic assessment of a wide range of climate variables relevant to general tourism activities and its capacity to compare the relative climatic merits of tourist destinations worldwide with widely available climate data.

\subsection{Climate data and climate change scenarios}

A total of 143 North American cities were selected for this analysis: 90 in the USA, 44 in Canada, and 9 in Mexico. The cities were selected on the basis of 3 criteria: significance as tourist destinations, data availability, and regional spatial representation. Current climate conditions were based on climatological normals for the period 1961-1990. Current climate data for cities in the USA were obtained from the National Climate Data Center (NCDC) of the National Oceanic and Atmospheric Administration (NOAA); data for Canadian cities were obtained from the Meteorological Service of Canada (MSC); data for Mexico were acquired from the World Meteorological Organization (WMO 1996). Strictly speaking, because microclimate effects (elevation, aspect, vegetation, proximity to water, urban density) can create variations in climatic conditions between the weather station and areas of local tourist activity, the TCI evaluation is only valid for the location of the weather station at the tourism destinations assessed.
The climate change scenarios used in this analysis were obtained from the Canadian Climate Impact Scenarios Project (CCIS 2002). The scenarios provided by CCIS have been constructed in accordance with the recommendations of the Intergovernmental Panel on Climate Change's (IPCC) Task Group on Scenarios for Climate Impact Assessment (TGCIA). The scenarios are derived from climate change experiments undertaken at international climate modeling centres that meet the criteria established by TGCIA. The scenarios are derived from 30 yr means (2040-2069 to the 2050s scenario, and 2070-2099 to the 2080s scenario), and represent change with respect to the 1961-1990 modeled baseline period. The monthly change values for the climate variables were determined from the average of the general circulation model (GCM) grid boxes within $2.5^{\circ}$ latitude/longitude of the geocentroid of each city included in the analysis. The number of grid boxes used to calculate the change depended on the GCM resolution, and to some extent on where the geocentroid of the city was located within each GCM grid. Generally, the change fields for the climate variables were calculated from an average of 4 to 6 GCM grid boxes.

The range of climate variables required for this analysis restricted the use of climate change scenarios to those from $2 \mathrm{GCMs}$. The monthly change values for the following variables were obtained from the Canadian Centre for Climatic Modelling and Analysis (CGCM2) and the UK Hadley Centre (HadCM3) GCMs: minimum and maximum temperature, relative humidity, total precipitation, and average wind speed. Changes in monthly sunshine amount were not available from the GCMs and therefore remain unchanged in the calculations of TCI rating under future climate change scenarios.

In order to examine the implications of a wide range of possible climate futures, scenarios that represented the upper and lower bounds of annual change in mean temperature and precipitation across North America were selected for this analysis. The emission scenarios considered for this study were based on IPCC (2000). The CGCM2-B2 scenario represented the lower bounds of change of the scenarios available, while the HadCM3-A1F1 scenario represented the upper bounds of change (circled scenarios in Fig. 1). Notably, when compared to other GCMs that did not provide the necessary range of climate variables for this analysis (Fig. 1), the scenarios used in this analysis did not represent the full range of possible climate future projected by GCMs. When the full range of scenarios in Fig. 1 is considered, the CGCM2-B2 scenario continues to represent the least change scenario, but scenarios from the Japanese GCM (CCSR-98) are 2 to $3^{\circ} \mathrm{C}$ warmer than the 


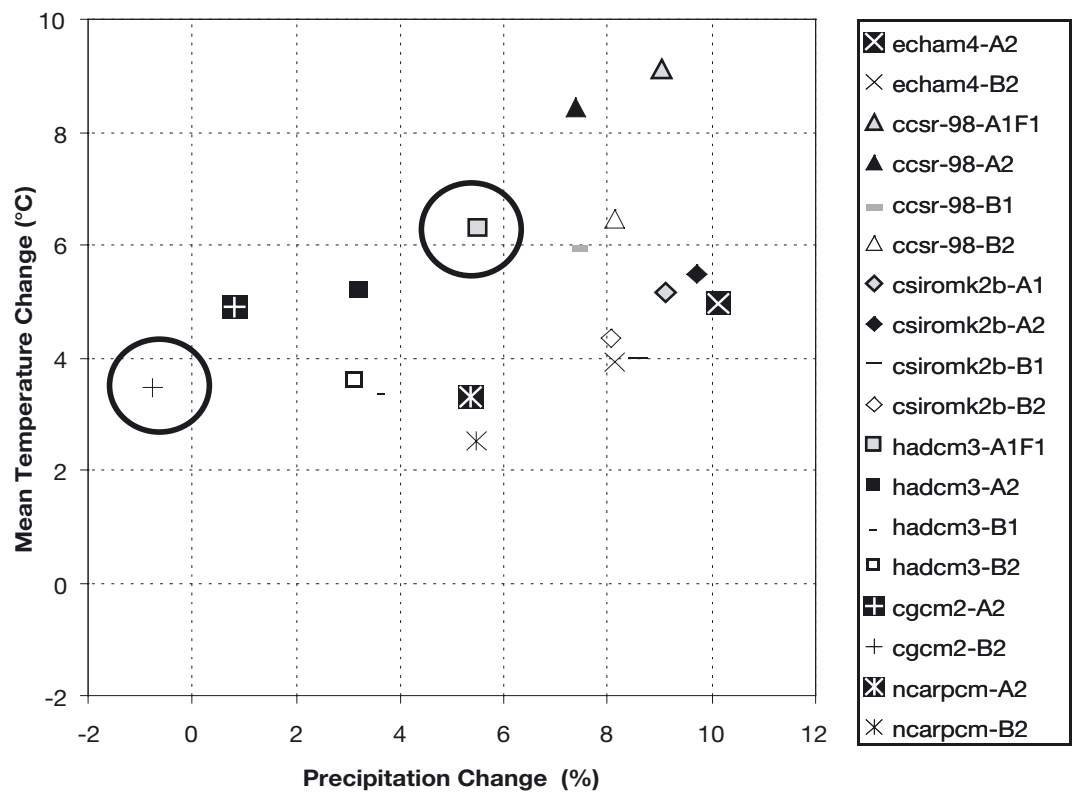

Fig. 1. Comparison of climate change scenarios for North America in the 2080s (land area only)

HadCM3-A1F1 scenario. In this respect, this analysis represents conservative estimates of the possible upper bounds of change in the climate resource for general tourism activities.

\subsection{Spatial analysis}

The ArcMap geographic information system (GIS) was used in this analysis. Monthly TCI data for the 1961-1990 baseline period and 4 climate change scenarios (CGCM2-B2: 2050s, 2080s; HadCM3-A1F1: 2050s, 2080s) were 'joined' to the base map to display spatial and temporal distributions. The interpolation process used the tension method of the spline technique in ArcMap. The spline technique estimates values using a mathematical function to create a line of best fit that minimized overall curvature between data intervals (Konecny 2003). The effects of elevation were not incorporated in this interpolation process. Data intervals for the interpolation mapping process were set at values of 10 to reflect the different TCI rating classes (Table 2).

\subsection{Annual tourism climate typology}

Scott \& McBoyle (2001) theorized that the tourism climate resource of every destination could be classified into one of 6 annual distributions (Fig. 2). Their tourism climate typology ranged from an 'optimal' year-round tourism climate (TCI $\geq 80$ for each month of

the year) through to a 'poor' yearround tourism climate (TCI $<40$ throughout the year). The 'summer' and 'winter peak' curves are similar, but distinguished by the season in which more favourable climatic conditions occur. A 'summer peak' is indicative of mid- to high-latitude locations where summer is the most pleasant period of the year for tourism. A 'winter peak' would occur in more equatorial and lower-latitude locations where cooler and/or lower humidity conditions in winter are more comfortable for tourists compared to hot and/or humid summer conditions. Where spring and fall months are more suitable for tourist activity a 'bimodal' or 'shoulder peak' distribution occurs. The tourism climate resource in regions with distinct wet and dry seasons (e.g. monsoon regions of Asia) will be determined to a large extent by precipitation, displaying a peak during the dry season, when the climate is more conducive to tourism activities. When Scott \& McBoyle (2001) examined the monthly hotel/resort accommodation costs (as a measure of tourism demand) at selected locations, they found these costs followed a similar annual pattern as the tourism climate resource rated with the TCI, suggesting the TCI has some validity in the tourism marketplace.
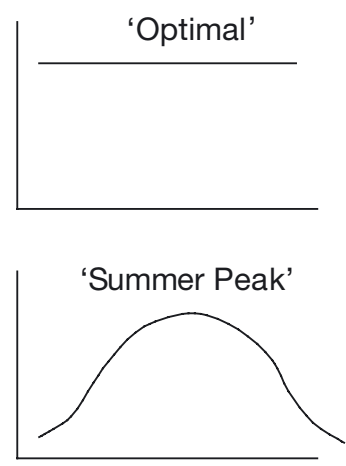

'Bi-modal - Shoulder Peaks'

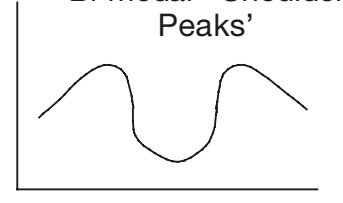

Months (Jan-Dec)

Fig. 2. Conceptual typology of annual tourism climates

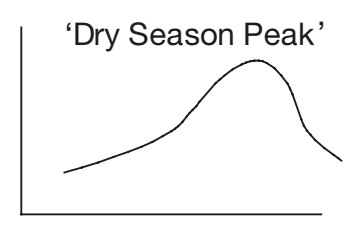

'Winter Peak'

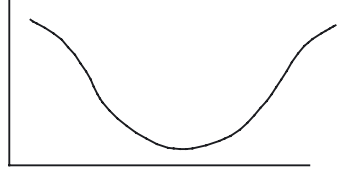




\section{RESULTS}

\subsection{Current (1961-1990) distribution of climate resources for tourism}

Of the 6 annual tourism climate types identified by Scott \& McBoyle (2001) (Fig. 2), 4 were found among the sample of North America destinations included in this analysis of current climate (summer peak, winter peak, bi-modal shoulder peak, optimal). The annual TCI curves of 4 cities that illustrate these tourism climate types are provided in Fig. 3. Fig. 4 then displays the spatial distribution of this tourism climate typology across North America. All of the Canadian cities, regardless of latitude or coastal location, were classified as summer peak destinations. In contrast, Mexican cities were all winter peak destinations, with 2 exceptions caused by the cooler temperatures of higher elevation. The distribution of TCI classes for cities in the USA was more diverse, encompassing 4 of the 6 typologies. Cities north of $40^{\circ} \mathrm{N}$ latitude were predominantly classified as summer peak destinations. Cities between 30 and $40^{\circ} \mathrm{N}$ latitude, with the exceptions of Roswell and Albuquerque, New Mexico, fell into the bimodal-shoulder peak class. Cities in the southern regions of Florida and Texas were classified as winter peak destinations. An optimal climate for tourism was found in southern California, where the cities of San Diego and Los Angeles were in or very near the 'excellent' category year-round.

Not all destinations fit perfectly within this typology. In the Hawaiian Islands the climate resource for tourism is fairly constant in the 65-79 range throughout the year, although ratings in the 80s occur in late winter and early spring. This consistent year-round distribution is similar to the 'optimal' and 'poor' typologies, but the TCI scores were not sufficiently high to classify the islands as an 'optimal' climate (TCI > 80 every month). Instead the Hawaiian Islands were

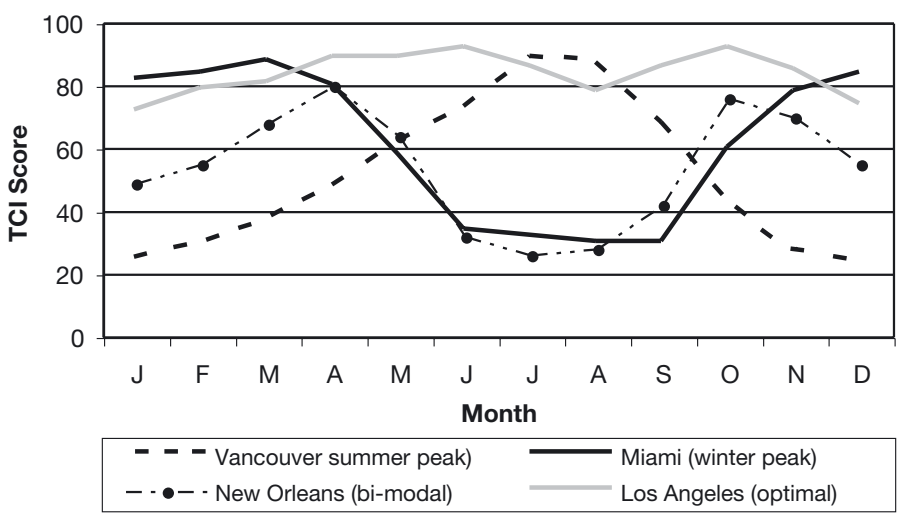

Fig. 3. Tourism climate ratings (1961-1990) at selected North American destinations

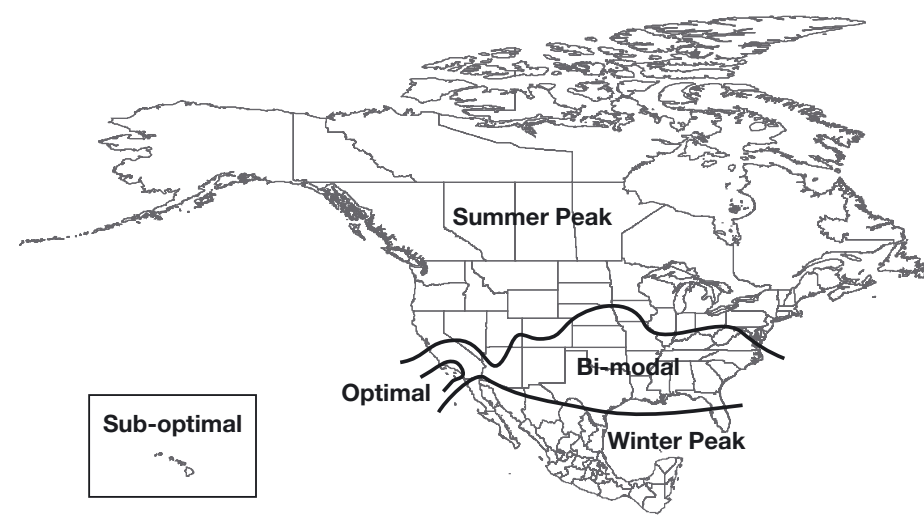

Fig. 4. Distribution of annual tourism climates (1961-1990)

labelled 'sub-optimal,' reflecting their 'good to very good' climate for general tourism activities year round.

The seasonal distribution (January, April, July, October) of climate resources for tourism (TCI categories 'good' to 'ideal') in North America is illustrated in Fig. 5. In January, the best climate resources for general tourism activities are concentrated in the southern USA and in Mexico. The best climate for winter sun holidays is found in southern Florida, southern Arizona, the Gulf of California and the Veracruz to Tampico coastline of Mexico. In April, TCI > 60 are generally found south of $40^{\circ} \mathrm{N}$ latitude. 'Excellent' climatic conditions exist over most of northern Mexico, California, New Mexico, western Texas, Florida and parts of Georgia and South Carolina. A region of 'ideal' conditions (TCI > 90) stretches along the border of the USA and Mexico from California to Texas. The best climate for general tourism activities during the peak tourism month of July was found in southern Canada and parts of the Great Lakes, northern Plains and Pacific Northwest of the USA. The 'ideal' TCI rating for areas of the southern Canadian Prairie provinces was unexpected, as climate is not a tourism resource that has been strongly marketed by this region. Equally unexpected was the finding that the long freshwater beaches of the Great Lakes, particularly Lakes Huron and Michigan, are climatically superior to the beaches of the eastern seaboard of the USA. Also notable was the 'excellent' rating found at high latitudes over much of Canada's northern Territories (Yukon and Northwest) and parts of Alaska. With the onset of autumn, the most advantageous climate for general tourism activities shifts to a region between approximately 42 and $28^{\circ} \mathrm{N}$.

\subsection{Climate resources for tourism under projected climate change}

With the different magnitude of projected warming between the greenhouse gas emission scenarios used 


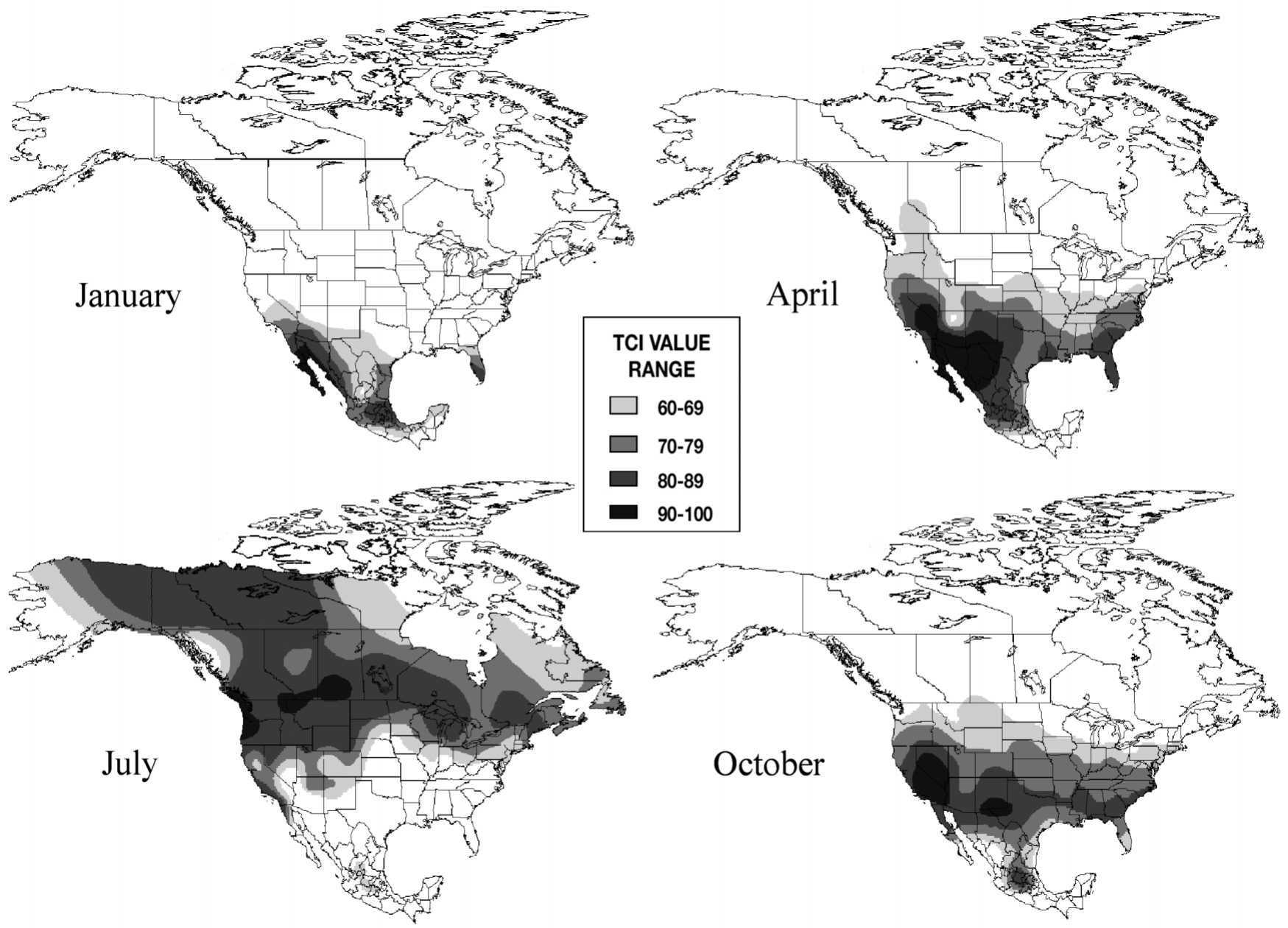

Fig. 5. Seasonal distribution of tourism climate resource (1961-1990)

to force the GCMs and the disparate regional representations of climate change in the 2 GCMs, dissimilarities in the redistribution of climate resources for tourism were anticipated. This was indeed the situation and consequently the results for the CGCM2-B2 and HadCM3-A1F1scenarios are discussed separately and then compared in the analysis that follows.

The regional pattern of tourism climate types under the CGCM2-B2 and HadCM3-A1F1 scenario are shown for the 2050s and 2080s in Fig. 6. In the CGCM2-B2 scenario for the 2050s the present (1961-1990) boundary between summer peak and bimodal zones did not change noticeably in the NE USA or the Great Lakes region, but it shifted 500-600 km northward in parts of the Plains and Pacific Northwest regions of the USA. There was very little change in the boundary between bimodal and winter peak zones, with the exception of eastern Texas, which changed from a bimodal to a winter peak classification. Similarly, the optimal climate zone in southern California remained unchanged. The 2080s scenario revealed much the same regional patterns of change, with the boundary between the summer peak and bimodal zones shifting further north to the Canadian border in the Plains states. The winter peak boundary shifted further north into northern Texas and coastal areas of Georgia and South Carolina. Climate conditions for tourism worsened in southern Mexico, as additional warming surpassed the thermal comfort levels deemed suitable for general tourism activities.

The warmer HadCM3-A1F1 scenario created much greater changes in the regional pattern of tourism climate types. In the 2050s scenario, the boundary between the summer peak and bimodal zones was 500-700 km further north than at present and generally followed the USA-Canada border. The San Francisco area was the most notable exception, remaining a summer peak destination because of the moderating influence of the coast. The boundary between the bimodal and winter peak zones shifted approximately 300-400 km further north in the SE USA and Texas. A prominent change was the disappearance of the opti- 

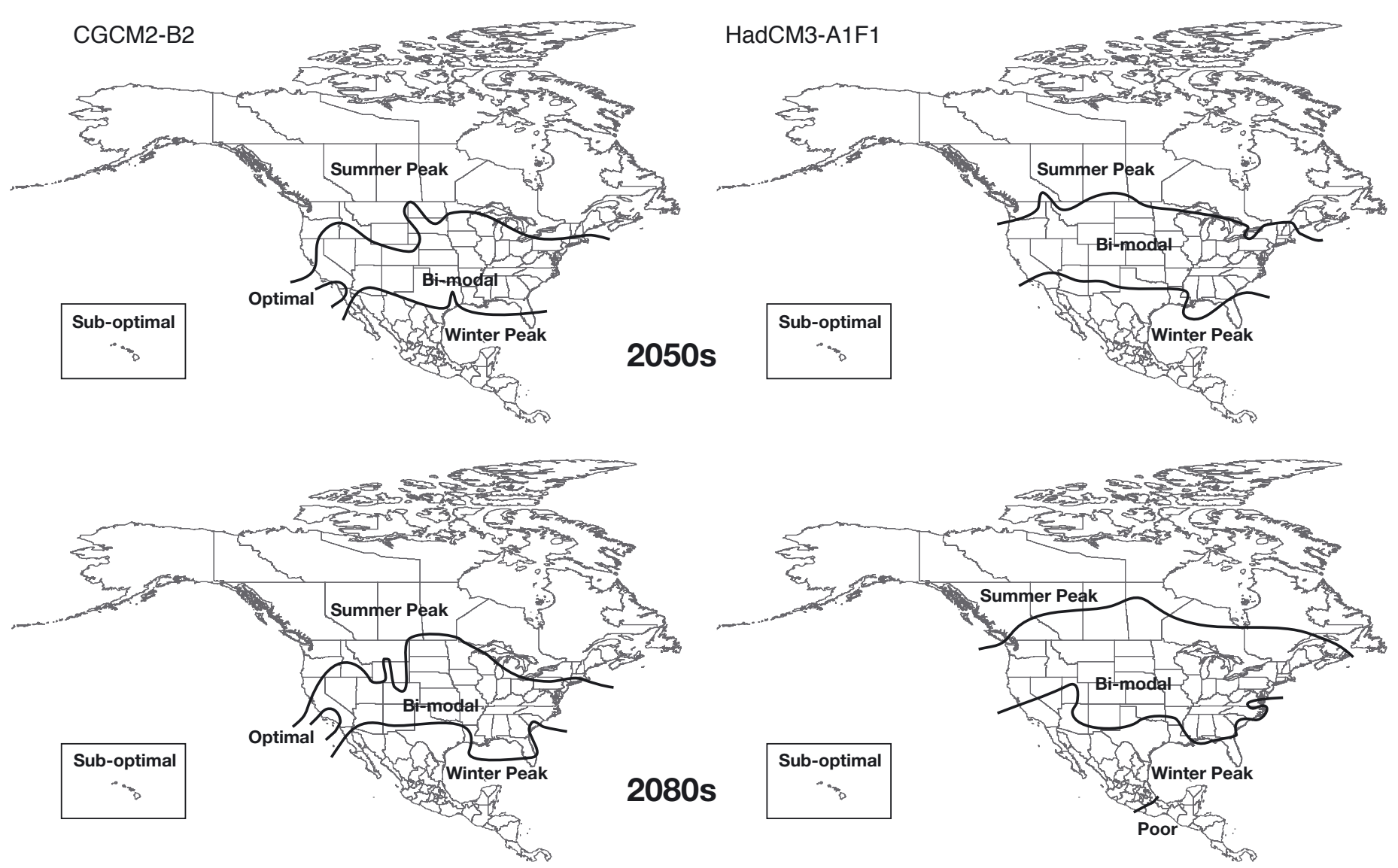

Fig. 6. Distribution of annual tourism climates under climate change scenarios

mal zone in southern California, which became a winter peak classification (Fig. 6) because summer temperatures exceeded thermal comfort levels for general tourism activities in the TCI. Overall, the HadCM3A1F1 2050s scenario projected change equal to or greater than the CGCM2-B2 2080s scenario, illustrating the importance of assessing a wide range of climatic futures. The HadCM3-A1F1 2080s scenario revealed extensive regional changes in tourism climate typologies. The boundary between the summer peak and bimodal zones shifted over $1000 \mathrm{~km}$ northward, altering the classification of most major cities in Canada. The southern margins of the bimodal zone did not change substantially from the HadCM3-A1F1 2050s scenario, although it now extended into parts of South Carolina and Utah. Hawaii's climate resources declined in each month of year in both the 2050s and 2080s climate change scenario. A poor climate zone in southern Mexico emerged in the HadCM3-A1F1 2080s scenario.

Analysis of the number of cities with 'excellent' or 'ideal' TCI ratings (TCI > 80) in the months of January and July (Table 3 ) revealed 2 salient findings. Examining January as illustrative of the winter sun holiday season, the number of cities in the USA with TCI ratings $\geq 80$ increased from 2 in the baseline period to 7 in the HadCM3-A1F1 2050s and CGCM2-B2 2080s scenarios and to 9 in the HadCM3-A1F1 2080s scenario. The implication is that current winter sunshine holiday destinations like southern Florida and Arizona would face increasing competition for winter sun holiday travellers and the seasonal 'snowbird' market (retirees from Canada and the northern USA who

Table 3. Number of cities with 'excellent' or 'ideal' tourism climate ratings $(\mathrm{TCI} \geq 80)$

\begin{tabular}{|lcrrrr|}
\hline & Present & \multicolumn{2}{c|}{ CGCM2-B2 } & \multicolumn{2}{c|}{ HadCM3-A1F1 } \\
& 1961-1990 & 2050s & 2080s & 2050s & 2080s \\
\hline January & & & & & \\
Canada & 0 & 0 & 0 & 0 & 0 \\
USA & 2 & 4 & 7 & 7 & 9 \\
Mexico & 6 & 6 & 4 & 4 & 1 \\
July & & & & & \\
Canada & 22 & 24 & 22 & 17 & 9 \\
USA & 19 & 6 & 6 & 2 & 1 \\
Mexico & 0 & 0 & 0 & 0 & 0 \\
\hline
\end{tabular}




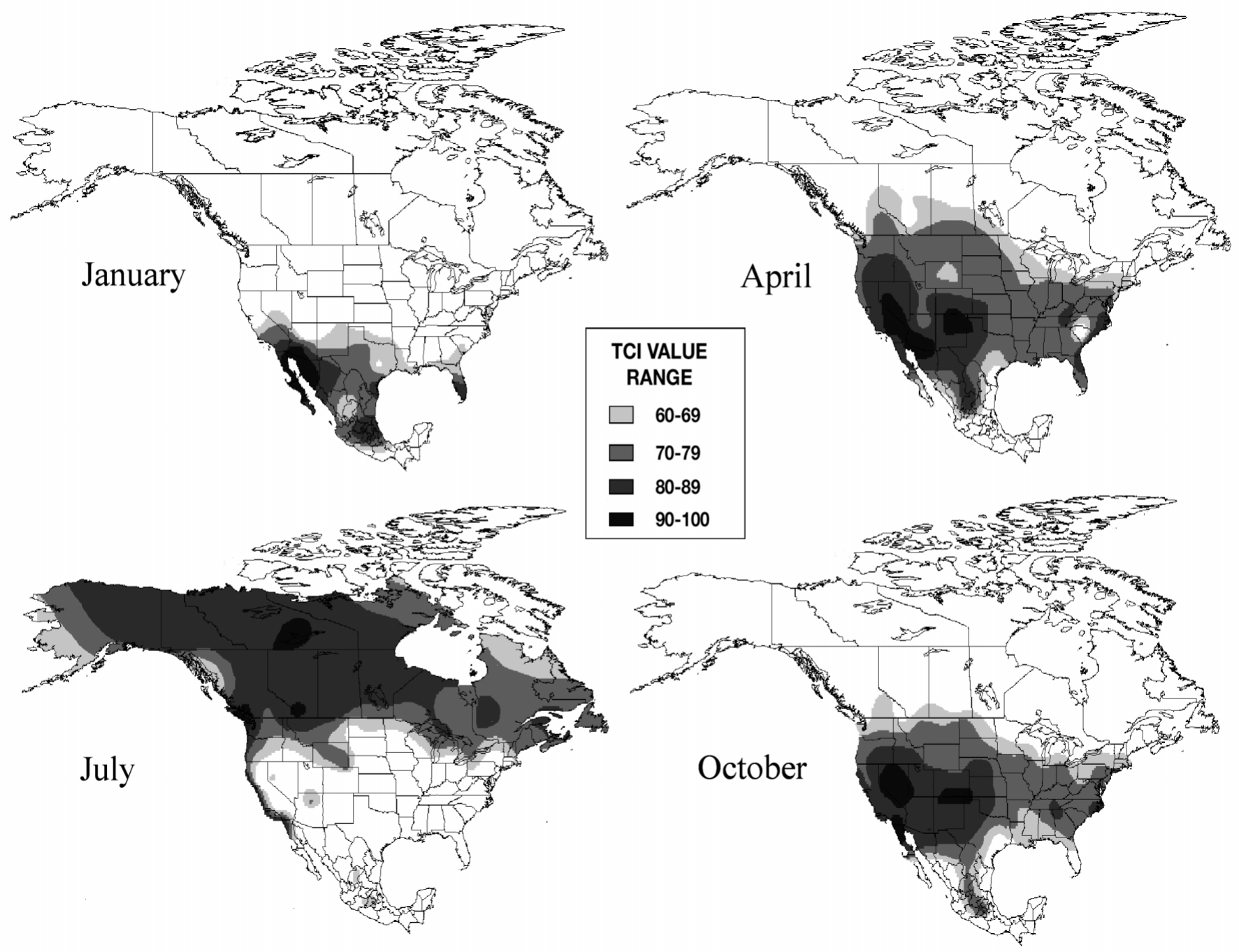

Fig. 7. Seasonal distribution of tourism climate resource (CGCM2-B2 2080s)

spend 2 to 6 mo in winter peak and optimal climate destinations). In contrast, the number of Mexican cities with TCI ratings $\geq 80$ in January decreased from 6 to 4 in the CGCM2-B2 scenario and to 1 in the HadCM3A1F1 2080s scenario, suggesting that Mexico could become less competitive as a winter sun holiday destination.

Examining July as illustrative of the peak summer holiday period in North America, there are strong contrasts in the potential impact of climate change on the climate resources for tourism in Canada and the USA. The number of Canadian cities with TCI ratings $\geq 80$ increased from 22 to 24 in the CGCM2-B2 2050s scenario, only to return to 22 in the 2080s scenario. The warmer and wetter HadCM3-A1F1 scenario did not provide the positive outcomes of the CGCM2-B2 scenario, projecting the number of Canadian cities with ratings $\geq 80$ to decline steadily over the 21 st century. In the USA the number of cities with TCI ratings $\geq 80$ decreased markedly from 19 to 6 or 2 in the 2050s (CGCM2-B2 and HadCM3-A1F1 scenarios, respectively). One implication is a continued growth in the 'sunbird' tourism market that is characterized by travel to more northern locations to escape the summer heat in the southern USA.

These spatial shifts in the seasonal climate resources for tourism in North America are also illustrated in the 2080s scenarios in Figs. 7 (CGCM2-B2) \& 8 (HadCM3A1F1). The CGCM2-B2 scenario for the 2080s projected only minor changes in January, compared to that of 2050, with an extension of the 'very good' (70-79) category in north-central Mexico and extension of the 'good' (60-69) category in northern Texas, New Mexico and western Louisiana. There is a large northward expansion of the 'very good' category in April, as much as $1200 \mathrm{~km}$ in the continental interior. While there is some retreat at the southern margins, more of North America benefits from quality climate 


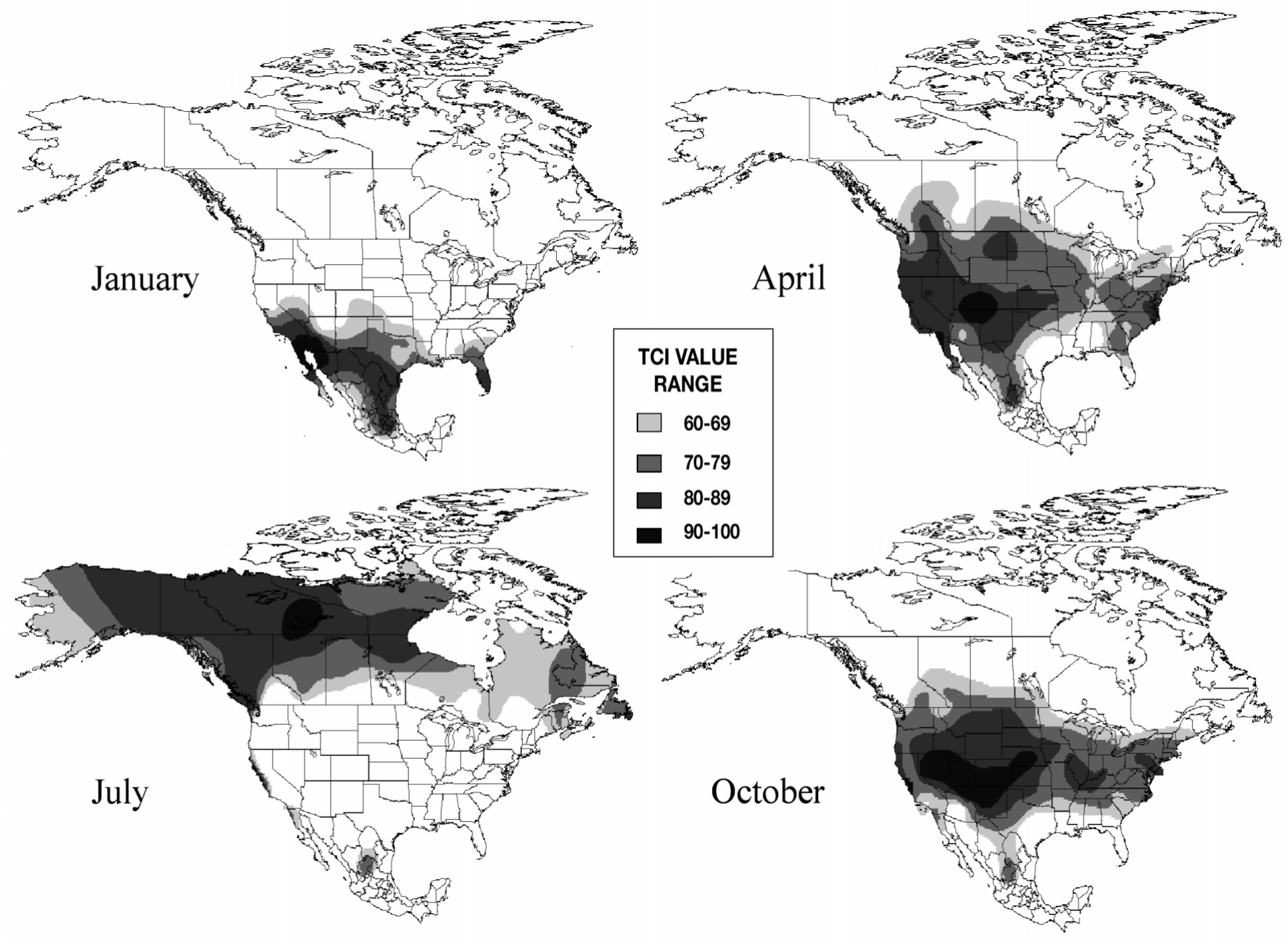

Fig. 8. Seasonal distribution of tourism climate resource (HadCM3-A1F1 2080s)

conditions for tourism in this scenario. As Fig. 7 indicates, TCI ratings of $\geq 60$ in July are largely restricted to Canada in this scenario. Compared with the baseline period, the 'excellent' climate of the Pacific Northwest and northern Plains states has retreated northward. The spatial pattern in October is generally similar to the baseline period, though each of the zones shifted slightly north in most regions.

Change in the seasonal distribution of climate resources for tourism is more marked in the HadCM3A1F1 scenario for the 2080s (Fig. 8). In January, there is an expansion of the 'excellent' (80-89) category in northern Mexico, southern California and western Texas, which could mean greater competition for the winter sun holiday market. Consistent with the CGCM2-B2 scenario in April, there is a large expansion of the 'excellent' (80-89) and 'very good' (70-79) categories in the NW and central USA. Unlike the CGCM2-B2 scenario, there is also a notable retreat at the southern margins, particularly in Florida, Texas, Louisiana and Alabama. In July the best climatic conditions for tourism are generally found north of $50^{\circ} \mathrm{N}$ latitude, except on Canada's Pacific and Atlantic coasts and close to the Rocky Mountains in the Province of Alberta. The October scenario is also largely consistent with the CGCM2-B2 scenario, with a 250-500 km northward shift in the 'very good' (70-79) category and expansion of the 'excellent' (80-89) category in Nevada, Utah, Colorado and New Mexico.

As with most climate change assessments there are regions that may benefit from new opportunities associated with improved climate resources for tourism, while other regions are at risk to adverse impacts. The previous discussion identified the macro-scale projected changes in the spatial distribution of climate resources for tourism in North America. Figs. 9 \& 10 illustrate how the climate resource for tourism may change at 4 well-known tourism destinations. Vancou- 

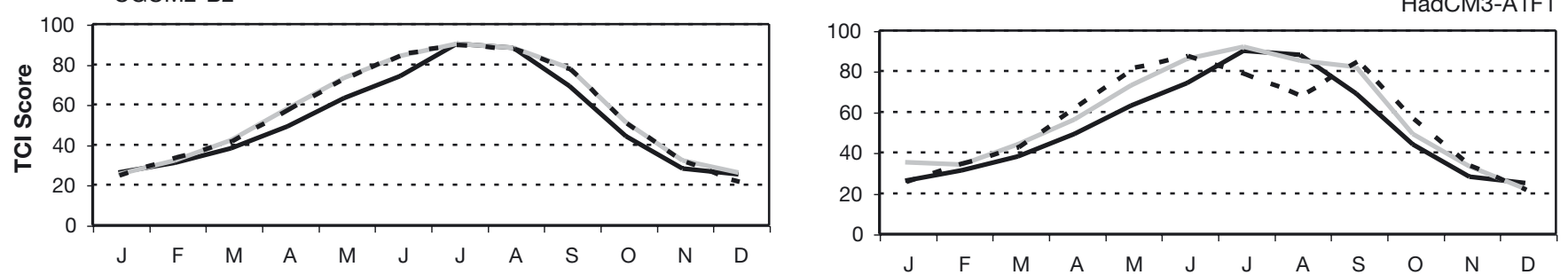

CGCM2-B2

Los Angeles, California
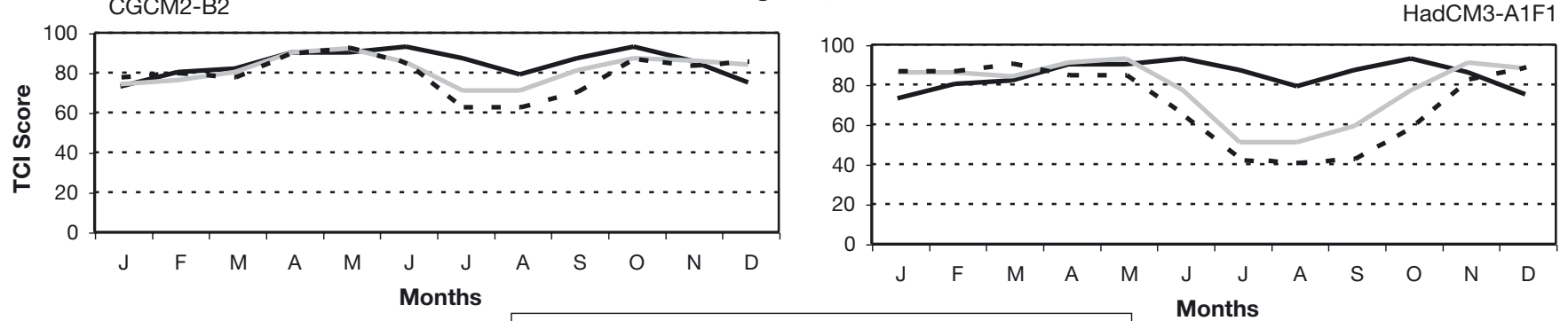

1961-90

$2050 s=-2080 s$

Fig. 9. Projected monthly change in TCI rating under climate change
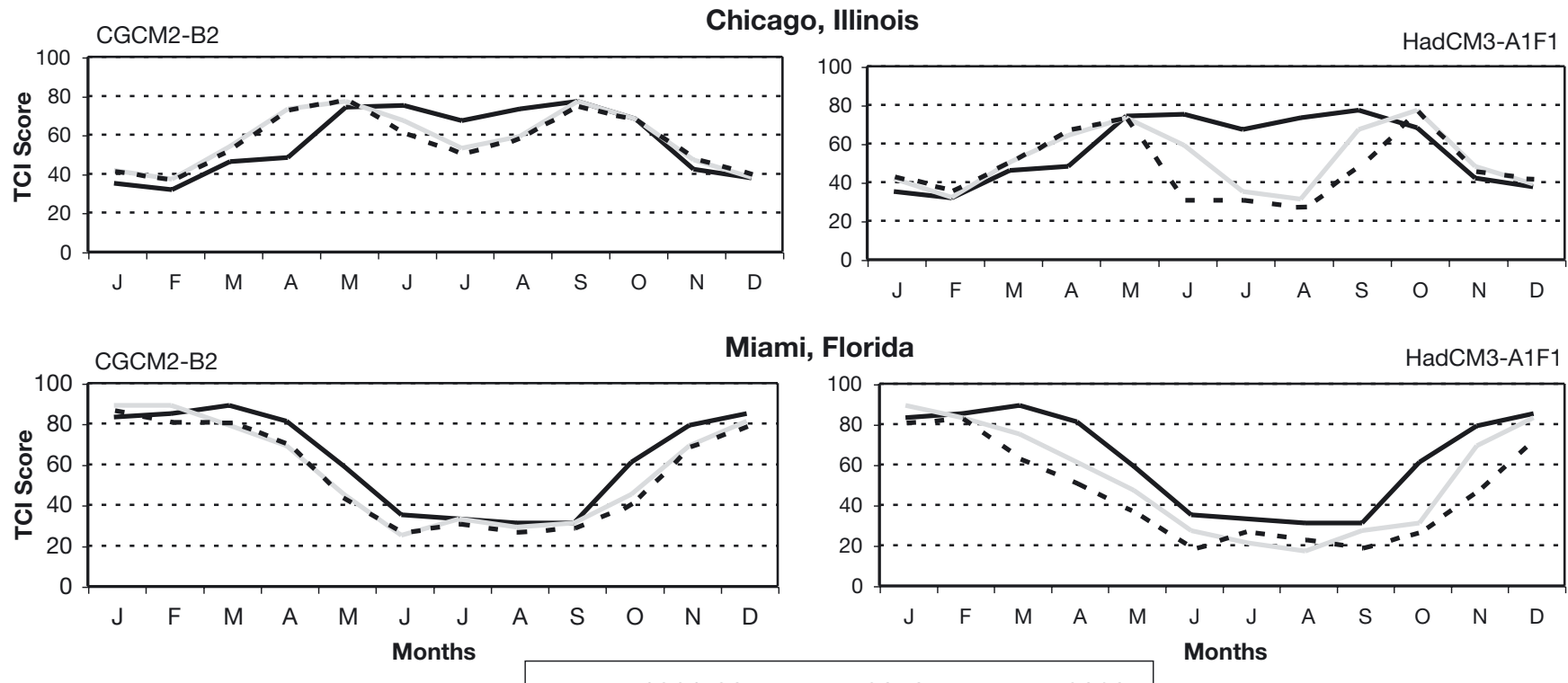

Miami, Florida

HadCM3-A1F1

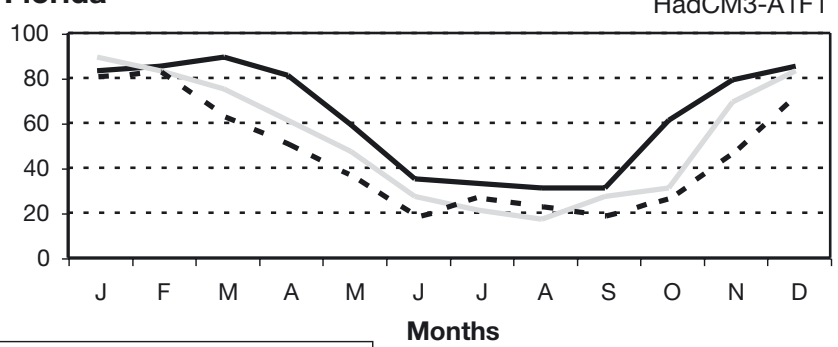

$1961-90$ 2050s

$-2080 s$

Fig. 10. Projected monthly change in TCI ranting under climate change

ver (British Columbia) exemplifies a region that would benefit from an improved climate for tourism as a result of projected climate change. In both CGCM2-B2 scenarios, there is an improvement in the climate for tourism in almost every month of the year. Approximately 1.5 mo with a climate rating of 'Good' or better $(\geq 60)$ have been added to the tourism season in Vancouver. The HadCM3-A1F1 scenario for the 2050s also improved most months, adding 2 additional months with 'excellent' $(\geq 80)$ ratings, while the 2080s scenario had a slightly detrimental impact on the key tourism months of July and August, giving Vancouver a bimodal tourism climate typology.

The climate for tourism in Los Angeles (California) benefited slightly in the winter months from both climate change scenarios; however the TCI ratings were 
lower from June to October in all scenarios. The impact of the HadCM3-A1F1 scenario for the 2080s is quite prominent, reducing the TCI rating in Los Angeles from the mid-80s ('excellent') to around 40 ('marginal' to 'unfavourable'). As mentioned, in the HadCM3A1F1 scenarios, Los Angeles shifts from an optimal tourism climate to a winter peak typology.

Improvements to the climate for tourism in Chicago (Illinois) occur mainly in the spring (March and April). The CGCM2-B2 scenario has a minor negative impact during the summer months. The HadCM3-A1F1 scenario had a much more pronounced effect during the summer period, with warmer temperature reducing the TCI rating by more than 30 points from June to September in the 2080s scenario. Chicago's tourism climate also changed from a summer peak to a bimodal shoulder peak classification.

Miami (Florida) provides an example opposite to Vancouver. While Vancouver's climate for tourism improved year-round as a result of climate change, both the CGCM2-B2 and HadCM3-A1F1 scenarios adversely impacted Miami's climate in all months except January. Nonetheless, Miami's climate is still highly rated $(>70)$ during the winter season.

\section{CONCLUSIONS}

The analysis found that a substantive redistribution of climate resources for tourism was possible as a result of projected climate change, particularly in the warmer HadCM3-A1F1 scenario and the later decades of the 21 st century. The projected changes in the tourism climate resource could have implications for intra- and inter-regional travel as well as international travel. As the case studies of Vancouver and Miami illustrate, different tourism destinations are likely to be 'winners' and 'losers' under climate change, with some benefiting from an improved and extended warm-weather tourism season and others suffering from climatic conditions less conducive to general tourism activities and perhaps reduced tourism demand.

Tourism in areas of the northern USA and Canada appeared to be potential beneficiaries of projected climate change. These regions are currently climate-limited for warm-weather tourism, and a longer, improved warm-weather tourism season would bring new opportunities for these regions. Tourism in Canada for example displays marked seasonality with $43 \%$ of domestic and $62 \%$ of international tourism expenditures occurring in the third quarter, July-September (Wilton \& Wirjanto 1998). This concentration of tourism expenditures in the warm-weather summer months suggests that a lengthened summer season would provide an opportunity for Canada to expand its domestic and international tourism markets. Less comfortable conditions and increased heat stress in many of the large urban centres in the USA (USNAT 2000) may increase the 'sunbird' tourism market, with much of southern Canada providing climatically suitable destinations.

Shorter and less severe winters may also reduce the impetus for Canadians to travel to warm-weather destinations as a winter escape. Canadians spent US $\$ 3.3$ billion traveling to warm-weather destinations (Arizona, Australia, California, Cuba, Dominican Republic, Florida, Hawaii, Mexico and Texas) in 1997. The combined affect of an increase 'pull factor' in the warm-weather travel season and a decreased 'push factor' during the winter months has potentially positive implications for Canada's international tourism trade balance, which was a US\$1.4 billion deficit in 2000 (CTC 2001). Hamilton \& Tol's (2003) analysis of tourism arrivals and departures under climate change scenarios supports this hypothesis. This optimism must be tempered by the range of potential negative impacts climate change could have on other Canadian tourism resources, particularly the environmental resource base that supports the large nature-based tourism market (Scott 2004).

With additional cities gaining climates suitable for winter sun vacations, there will be increased destination choice and competition for the short-term winter sun holiday and the seasonal 'snowbird' market. This would present new opportunities in some regions (e.g. Georgia and South Carolina), while potentially reducing the market share of leading current destinations such as southern Florida, Arizona and particularly Mexico.

Uncertainties regarding the potential impacts of climate change on the environmental resources for tourism (e.g. sea level rise, water supply, biodiversity), how tourists will adapt to climatic, environmental and social conditions resulting from global change, and the preferences of tourists 50 to $80 \mathrm{yr}$ from now, currently preclude any definitive statement regarding the net impact of climate change on the tourism industry of North America. We join the WTO (2003) in emphasizing the strong need for additional research on the implications of climate change for the tourism sector and emphasize that enhanced collaboration between tourism stakeholders and the climate change assessment community is paramount for progress in this field.

\section{LITERATURE CITED}

Agnew M (1995) Tourism. In: Palutikof J, Subak S, Agnew M (eds) Economic impacts of the hot summer and unusually warm year of 1995. Department of the Environment Report, Norwich, p 139-147 
Becker S (2000) Bioclimatological rating of cities and resorts in South Africa according to the climate index. Int J Climatol 20:1403-1414

Besancenot J, Mouiner J, De Lavenne F (1978) Les conditions climatiques du tourisme littoral. Norois 99:357-382.

Boniface B, Cooper C (1994) The geography of travel and tourism. Butterworth-Heinemann, Oxford

Boyd W, Bulter R, Haider W, Perera A (1994) Identifying areas for ecotourism in northern Ontario: application of a GIS methodology. J Appl Recreation Res 19:41-66

Burnet L (1963) Villégiature et tourisme sur les côtes de la France. Hachette, Paris

CBC (2004) Travel and tourism. Conference Board of Canada; www.conferenceboard.ca/ctri/default.htm

CCIS (2002) Canadian Climate Impact Scenarios Project; www.cics.uvic.ca/scenarios/

CTC (2001) Canadian Tourism Commission Research Report - 28 June 2001. Canadian Tourism Commission, Ottawa

Crowe RB (1976) A climatic classification of the Northwest Territories for recreation and tourism. Environment Canada, Toronto

Dammann W (1964) Die Schwüle als Klimafaktor. Ber Dtsch Landesk 32:100-109

Danilova NA (1973) Klimat pribaltiki i prodolzhitelnost perioda blagopriyatnogo dia turizma. In: Kolalev JA (ed) Geografia i turism. Voprosy Geografii 93:164-176

de Freitas C (1990) Recreation climate assessment. Int J Climatol 10:89-103

de Freitas C (2003) Tourism climatology: evaluating environmental information for decision making and business planning in the recreation and tourism sector. Int J Biometeorology 48:45-54

Giles A, Perry A (1998) The use of a temporal analogue to investigate the possible impact of projected global warming on the UK tourist industry. Tourism Manage 19:75-80

Hamilton J, Tol R (2003) The implications of climate change to tourism-commentary paper. In: Proc Eur Sci Found Explor Workshop on Climate Change, the Environment and Tourism. Milan, Italy. CD-ROM, Paper 6

Heurtier R (1968) Essaie de climatologie touristique synoptique de L'Europe occidentale et Mediterranéenne pendant la saison d'été. Météorologie 7:71-107

Hofer K (1967) Klimabehaglichkeit und Kurort. Wiener Med Wochenschr 16:444-446

IPCC (2000) Emission scenarios. A special report of the Intergovernmental Panel on Climate Change, Working Group 3. Summary for policy makers. IPCC, Geneva

Jansen-Verbecke M (2001) Urban tourism and tourism research. In: Wall G (ed) Contemporary perspectives on tourism. Department of Geography Publication Series, Occasional Paper, University of Waterloo, Waterloo, Ontario, p 129-142

Jorgensen F, Solvoll G (1996) Demand models for inclusive tour charter: the Norwegian case. Tourism Manage 17: $17-24$

Kandror I, Demina D, Ratner Y (1974) Fiziologicheskye principy sanitarno-klimatologicheskogo rayonirovanya territoriè SSSR. Meditsina, Moskva

Konecny G (2003) Geoinformation: remote sensing, photogrammertry and geographic information systems. Taylor \& Francis, London

Limb M, Spellman G (2001) Evaluating domestic tourists' attitudes to British weather: a qualitative approach. In: Matzarakis A, de Freitas C (eds) Proc 1st Int Workshop on Climate, Tourism and Recreation. International Society of

Editorial responsibility: Chris de Freitas,

Auckland, New Zealand
Biometeorology, Commission on Climate, Tourism and Recreation, Halkidi, p 1-14

Lohmann M, Kaim E (1999) Weather and holiday preference-image, attitude and experience. Rev Tourisme 2: $54-64$

Mieczkowski Z (1985) The tourism climatic index: a method of evaluating world climates for tourism. Can Geogr 29: $220-233$

Morgan R, Gatell E, Junyent R, Micallef A, Özhan E, Williams A (2000). An improved user-based beach climate index. J Coast Conserv 6:41-50

OMTR (2002) If the future were now: impacts of aging in the Canadian market on tourism in Ontario. Ontario Ministry of Tourism and Recreation, Toronto

Pegay C (1961) Precis de climatologie. Masson, Paris

Perry A (1997) Recreation and tourism. In: Thompson RD, Perry AH (eds) Applied climatology. Routledge, London, p 240-248

Scott D (2004) Climate change and sustainable tourism in the 21st century. In: Cukier J (ed) Tourism research: policy, planning and prospects. Department of Geography Publication Series, University of Waterloo, Ontario

Scott D, McBoyle G (2001) Using a 'tourism climate index' to examine the implications of climate change for climate as a natural resource for tourism. In: Matzarakis A, de Freitas C (eds) Proc 1st Int Workshop on Climate, Tourism and Recreation. International Society of Biometeorology, Commission on Climate, Tourism and Recreation, Halkidi, p 69-98

Smith K (1993) The influence of weather and climate on recreation and tourism. Weather 48:398-404

Steadman RG (1984) A universal scale of apparent temperature. J Clim Appl Meteorol 23:1674-1687

TIAA (2004) Impact of travel on state economies, 4th edn. Travel Industry Association of America; www.tia.org/ pubs/default.asp

USNAT (2000) Climate change impacts on the United States: the potential consequences of climate variability and change. United States National Assessment Team, US Global Change Research Program. Cambridge University Press, New York

Viner D, Amelung B (2003) Climate change, the environment and tourism: the interactions. In: Viner D, Amelung B (eds) Proc Eur Sci Found Life and Earth Sciences Workshop, Climatic Research Unit, Norwich

Wall G (1992) Tourism alternatives in an era of global climate change. In: Smith V, Eadington W (eds) Tourism alternatives. University of Pennsylvania Press, Philadelphia, p 194-236

Wall G (1998) Impacts of climate change on recreation and tourism. In: Responding to global climate changenational sectoral issues, Vol XII, Canada country study, Adaptation and Impacts Research Group. Environment Canada, Toronto, p 591-620

Wilton D, Wirjanto T (1998) An analysis of the seasonal variation in the national tourism indicators. Canadian Tourism Commission, Ottawa

WMO (1996) Climatological Normals (Clino) For the Period 1961-1990. World Meteorological Organization, Geneva

WTO (1998) Tourism 2020 vision. Publications Unit, World Tourism Organization, Madrid

WTO (2002) Tourism highlights 2001. Publications Unit, World Tourism Organization, Madrid

WTO (2003) Final report of the 1st International Conference on Climate Change and Tourism, Djerba, Tunisia. Publications Unit, World Tourism Organization, Madrid 